\title{
Fat Droplet Measurement
}

National Cancer Institute

\section{Source}

National Cancer Institute. Fat Droplet Measurement. NCI Thesaurus. Code C98728.

The determination of the amount of triglyceride aggregates present in a sample. 